\title{
POR UMA PEDAGOGIA PERFORMATIVA: A ESCOLA COMO ENTRELUGAR PARA PROFESSORES-PERFORMERS E ESTUDANTES-PERFORMERS
}

Gilberto Icle ${ }^{1}$

Mônica Torres Bonatto ${ }^{2}$

RESUMO: Este texto apresenta a possibilidade de pensar a performance em diferentes acepçóes; entre elas, aquelas que mostram a sua capacidade de desestabilizar a escola e o que sabemos sobre ela. Descrevem-se três experiências com alunos da educação básica e, a partir delas, desdobram-se noçóes com o intuito de circunscrever uma pedagogia performativa: a escola como entrelugar, em que se apresenta o conceito de liminar; e "professor-performer" e "estudante-performer", noçóes que procuram minimizar a diferença hierárquica entre professor e aluno.

Palavras-chave: Performance. Estudos da Performance. Educação. Educação Básica. Escola.

\section{For a Performative Pedagogy: the school} as a place for cultural hybridity for teacher-performer and the student-performer

ABSTRACT: This article describes the possibility for thinking about performance in different senses, namely among those that show its ability to disrupt the school and what we know

\footnotetext{
${ }^{1}$ Universidade Federal do Rio Grande do Sul, Faculdade de Educação - Porto Alegre (RS), Brasil. E-mail: gilbertoicle@gmail.com

${ }^{2}$ Universidade Federal do Rio Grande do Sul, Colégio de Aplicação - Porto Alegre (RS), Brasil. E-mail: mo.bonatto@gmail.com

DOI: $10.1590 / C C 0101-32622017168674$
} 
about it. Notions were extracted based on descriptions of three experiences with Basic Education students, the objective being to circumscribe a performative pedagogy: the school as a place for cultural hybridity in which the concept of boundary is present; and "teacher-performer" and "student-performer", notions that seek to minimize the hierarchy between teacher and student.

Keywords: Performance. Performance Studies. Education. School.

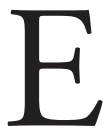

ste artigo, sob a forma de ensaio, propóe a reflexão sobre uma pedagogia performativa e o faz aproximando dois conceitos: a escola como entrelugar; e a reversibilidade dos papéis de professor-performer e aluno-performer. Tal intento será disparado a partir da descriçáo de três experiências performativas, que servem apenas como exemplos, realizadas na escola de educação básica.

Para dar seguimento à discussão proposta, tomaremos os Estudos da Performance como pano de fundo e a própria noção de performance e de performativo como anelo por intermédio do qual circunscreveremos pouco a pouco o que chamamos de pedagogia performativa.

Performanceé uma palavra da língua inglesa que não encontra correspondente em espanhol ou português, tendo sido incorporada na literatura acadêmica, ou mesmo em situaçōes cotidianas, sem tradução (TAYLOR, 2011). A noção de performance como linguagem, a Arte da Performance, reconhecida como expressão artística independente a partir da década de 1970, constituiu-se como um espaço para experimentaçóes, quebra de paradigmas e busca de novas formas de pensar e fazer arte, apoiado na concepçáo de que os processos são tão importantes quanto os produtos deles resultantes.

Em propostas dessa natureza, o que chega ao público é parte de um longo processo, que não começa ou termina com a ação ou o evento proposto pelo artista; a estrutura hierárquica é mais horizontalizada e flexível em relação aos papéis desempenhados por cada um dos participantes no processo de criação; o texto nunca está finalizado, pode ser, ainda, apenas um roteiro ou guia sujeito a alteraçóes constantes; raramente se representa ser outra pessoa (personagem), é a identidade do performer que se desvela frente ao público nas ações por ele propostas. 
Mas isso não é tudo. A noção de performance não se limita a acontecimentos artísticos. Tomada como um elemento essencial da experiência humana (PINEAU, 2005, p. 21), essa noção tem papel central nos trabalhos que ganharam espaço e visibilidade a partir do campo de pesquisa denominado Estudos da Performance, os quais

[...] oferecem uma rica gama de possibilidades, na qual a Performance e a performatividade aparecem como instrumentos pelos quais é possível pensar as relaçôes sociais, as políticas públicas, as identidades de gênero e de raça, a estética, a infância, o currículo, os rituais, a vida cotidiana, entre outros (ICLE, 2013, p. 16).

Assim, a potência da noção de performance no campo da educação, em especial na análise da escola, circunscreve-se não apenas no diagnóstico (pensar a escola como performance), mas também na proposição (pedagogias performativas), pois a qualidade da performance (o performativo) é a capacidade que ela tem de nos mostrar a transformação como fator essencial da ação humana: na performance fazemos alguma coisa que nos permite refazer-nos a nós mesmos.

Assim, neste artigo náo vamos discutir performance como modos de ensinar arte, mas como meio para desestabilizar aquilo que nós e nossos alunos sabemos sobre a escola.

\section{PERFORMANCE E EDUCAÇÃO}

O campo denominado Estudos da Performance surgiu nos anos 1970, constituindo-se como uma "disciplina interdisciplinar" (SCHECHNER, 2000, p. 12). Com foco nas complexas dinâmicas da sociedade atual, as pesquisas desse campo se dedicam a analisar o mundo como performance e vão além das performance formais (em especial do campo das artes), estudando, também, as performance da vida cotidiana, não apenas reposicionando as fronteiras entre as diferentes linguagens artísticas, mas entre a arte e a vida. 
A interseção da performance com a educação nos possibilita pensar para além da demarcação de saberes e conhecimentos, exigindo uma forma de organização pautada pela experiência coletiva. Quando voltam seu olhar para a pedagogia, os teóricos e pesquisadores identificados com os Estudos da Performance (GAROIAN, 1999; PINEAU, 2005, 2010, 2013; STUCKY; WIMMER, 2002) dedicam especial atenção às relações estabelecidas entre professores e estudantes e às marcas deixadas em seus corpos pelo processo de escolarização.

As situações de ensino-aprendizagem podem assumir características observadas em proposiçóes da Arte da Performance e, também, em alguns rituais, jogando com as subjetividades dos participantes e com a efemeridade dos processos, convertendo a sala de aula em um espaço de invenção e de criação; em um espaço liminal.

Na perspectiva de Charles Garoian, compreender a sala de aula como espaço liminal, que aqui chamamos de entrelugar, leva-nos a convocar os

estudantes a pensar e agir de forma crítica, desafiando os pressupostos históricos e culturais trabalhados nas escolas, em casa, nas instituiçóes religiosas, nos meios de comunicação e em outros espaços nos quais suas identidades e expressóes estão em risco (GAROIAN, 1999, p. 49).

A figura do performer, esse artista "[...] híbrido, que faz do próprio corpo a obra de arte" (ICLE, 2013, p. 11), provoca-nos a pensar o reposicionamento de professores e estudantes na contramáo da lógica vigente, oferecendo novas bases para a análise de práticas da educação básica e engendrando proposiçốes inéditas. Em processos dessa ordem, tal flexibilização das hierarquias se dá a partir do momento em que não há apenas uma voz de comando, mas uma coordenação realizada em colaboração, com os riscos que tais práticas impóem. As definiçóes se dão em ação, em performance.

A partir desse novo olhar sobre as açóes e os comportamentos humanos, os Estudos da Performance nos sugerem analisar o mundo como performance, esmiuçando aspectos e práticas da vida cotidiana e não apenas eventos espetaculares ou religiosos, nos quais o traço da ritualização é mais proeminente. Organizamo-nos em sociedade desempenhando 
papéis de acordo com as expectativas que recaem sobre eles e que conhecemos de antemão. É parte intrínseca a esse processo de reprodução, repetição, a potência para instaurar a ruptura, gerando uma perspectiva que ressignifica nosso olhar sobre estruturas cristalizadas e aponta para a importância de procurarmos as fissuras, as brechas que possibilitem novas formas de ser.

Assim, performance aqui, como operador para compreender e propor mudanças no âmbito da educação, significa, a um só tempo, a ritualização de comportamentos e a possibilidade inventiva de romper com essas repetiçóes.

\section{ENSINO-CRIAÇÃO: UMA ATITUDE PERFORMATIVA}

Dois trabalhos que compóem este dossiê, um de autoria de Carminda Mendes André e outro de Paulina Maria Caon, apresentam-se como suporte para a reflexáo sobre a sala de aula como espaço performativo. Foram realizados no ano de 2012 com uma turma de 34 jovens, entre 11 e 13 anos, estudantes do $7^{\circ}$ ano do ensino fundamental em uma escola da Rede Federal de Ensino em Porto Alegre (RS). Nesse grupo, tudo acontecia em alta velocidade, em especial os trajetos entre os diferentes ambientes da escola. Palavras, nem sempre amistosas, atravessavam a sala de aula a todo momento, até mesmo quando alguma atividade estava sendo desenvolvida com o acompanhamento dos professores. Essas eram manifestaçóes de corpos inquietos, incomodados, desacomodados.

Em resposta, os professores os pressionavam para o cumprimento de regras que garantissem a contenção de tais impulsos. Ao conversarmos sobre isso com o grupo, buscamos identificar as leis vigentes na escola. Iniciamos uma lista no quadro que ocupava uma das paredes da sala, para a qual, como de praxe, estavam voltados todos os alunos. $\mathrm{O}$ grupo destacou aspectos relacionados à utilizaçáo dos espaços coletivos e a questóes de conduta em sala de aula: náo correr, náo gritar, não bater, não "implicar" com os colegas e muitos outros impedimentos que buscavam trazer a ordem imaginada pelos adultos à desordem (também na opinião dos adultos) provocada pelas açôes dos estudantes. 
A partir de debate que fizemos sobre o tema, surgiu a proposta da realização de duas performance. A primeira delas consistia na produção de uma sequência de imagens com foco na padronização imposta na escola. Ela foi batizada como Book da Turma (Figuras 1 e 2), em alusão aos portfólios com fotografias produzidas por profissionais. Jogamos com a criação de imagens nas quais tentamos homogeneizar o que concluímos não ser, de fato, "homogeneizável".

Após realizarmos o trabalho de criação de imagens (Book da Tur$m a$ ), que refletia nossa crítica em relaçáo à imposição de modelos de conduta padronizados, partimos para a criaçáo de outra proposta: a segunda performance realizada pela turma de estudantes, na qual o debate, antes girando em torno das regras da escola e do que elas representavam, agora enfocava os deslocamentos, a ocupação do espaço escolar, as possibilidades de intervenção.

Como seria habitar o espaço da escola de outra forma, ainda que por um curto intervalo de tempo, buscando novos modos de relação com

\section{Figura 1}

Book da Turma I², Porto Alegre, 2012.

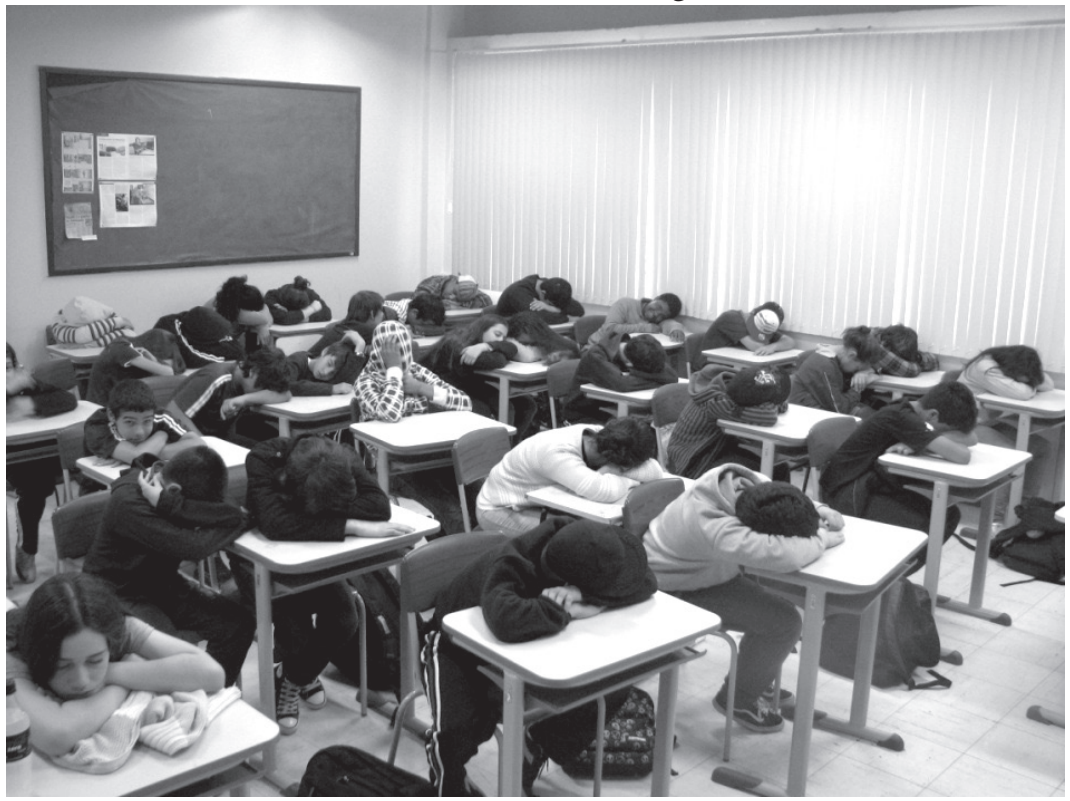

Fonte: Mônica Torres Bonatto. 
o ambiente escolar? Decidimos jogar com o ritmo, com a velocidade dos deslocamentos realizados por todos, fazendo um trajeto habitual e bastante conhecido de maneira nada usual, em câmera lenta. Acrescentamos, ainda, outro desafio: realizar o exercício com todo o grupo reunido, em sintonia.

Assim nasceu a performance Caminhada na Lua. A euforia do grupo foi transformada em contenção no momento em que descíamos a rampa em direção ao saguão da escola. Aqueles que estavam no andar térreo, trabalhando ou mesmo de passagem, tornaram-se subitamente espectadores do evento. A visão daquele grupo de estudantes, exatamente no momento em que deveriam estar em sala de aula, pareceu gerar certa inquietude.

Nas duas propostas apresentadas acima, o grupo partiu de uma discussão sobre as regras que regiam a conduta em sala de aula - trazendo como resultado a negação do protagonismo aos estudantes, na medida em que seus corpos eram anulados a cada nova ordem - , para, então, explorar a presença potencialmente transformadora desses corpos

\section{Figura 2.}

Book da Turma I, Porto Alegre, 2012.

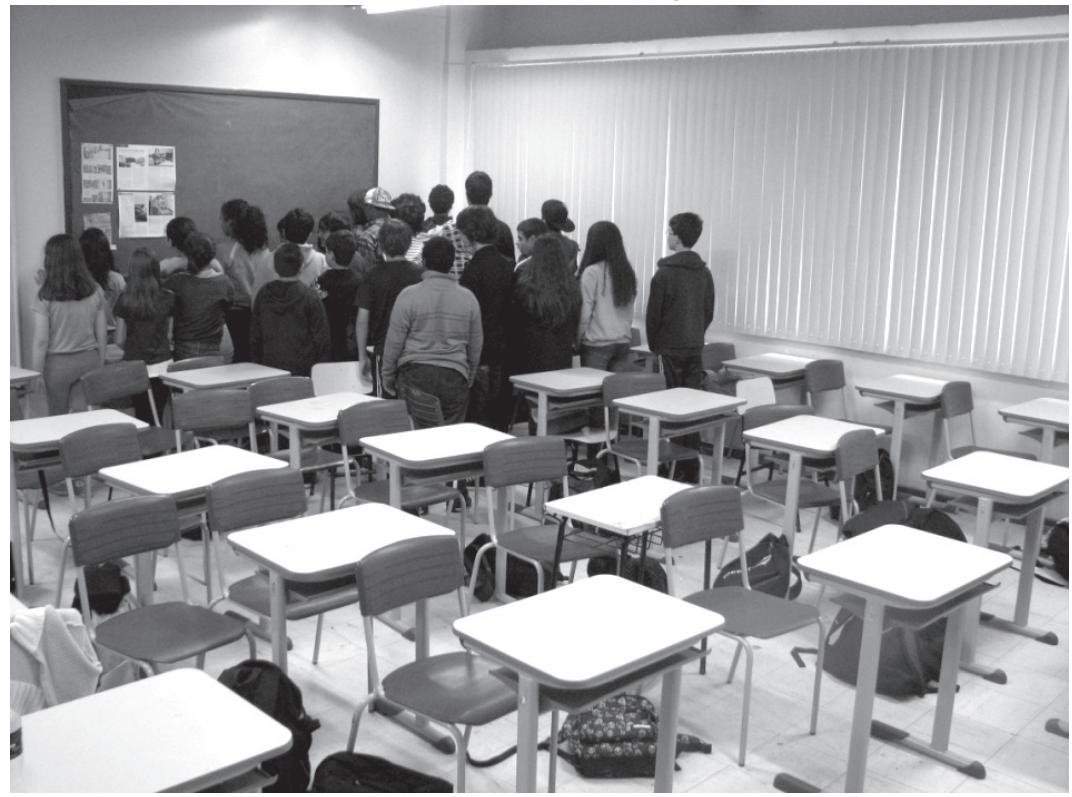

Fonte: Mônica Torres Bonatto. 
no ambiente escolar. Fomos da ausência à presença, discutidas pelas açóes que traziam, sem dúvida, a marca da ludicidade.

Nesse sentido, ganha destaque outro importante ponto de contato da performance com a educação: a possibilidade do reposicionamento dos envolvidos em processos de ensino-criaçáo a partir da constituiçáo do que aqui chamamos de atitude performativa, pautada pela ação, pela intervenção no cotidiano, pela busca por espaços de transformaçáo da realidade que encontramos nas escolas. Tal movimento está estreitamente vinculado à compreensão da importância da centralidade do corpo nos processos de ensino-aprendizagem, elemento fundamental para a constituição de propostas de ensino-criação.

A terceira performance que trazemos para análise foi realizada em 2014 (Figuras 3 e 4), após um período de quatro meses nos quais estudantes e professores estiveram imersos na leitura de textos, apreciação de vídeos, análise de peças publicitárias e em conversas com convidados, constituindo

\section{Figura 3}

Não existe cor certa I, Porto Alegre, 2014.

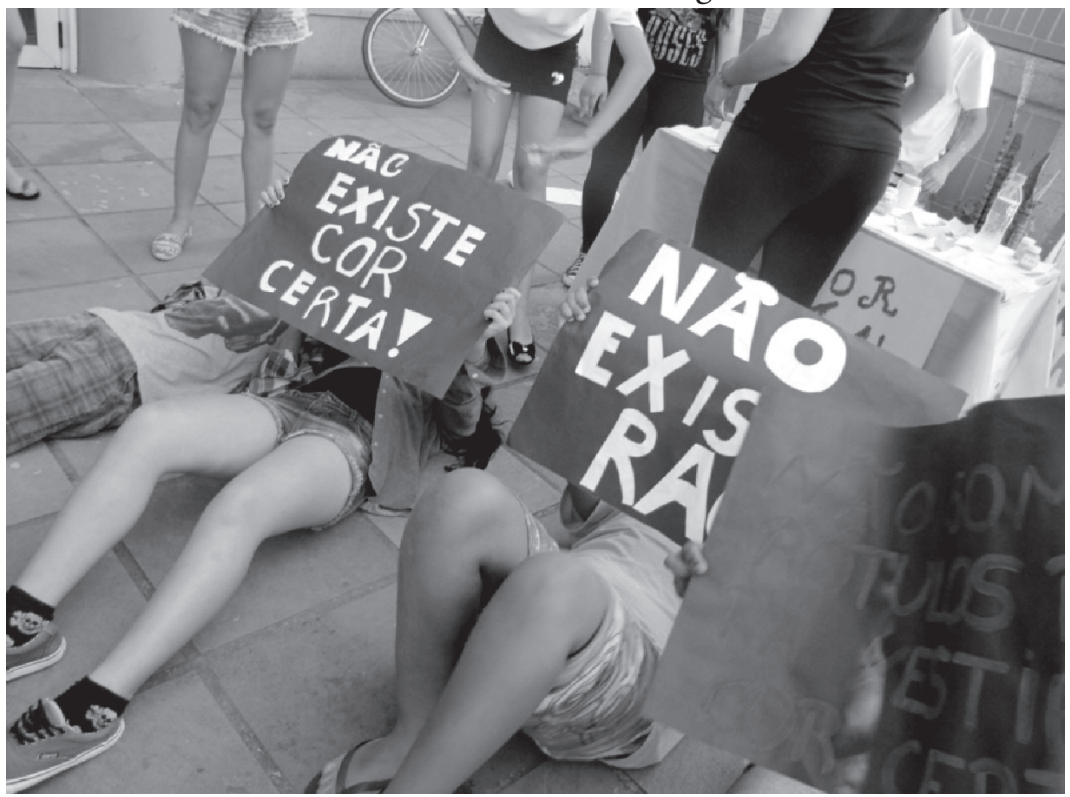

Fonte: Mônica Torres Bonatto. 
distintos momentos da proposta que ganhou o nome de Atividade Negritude. Tal atividade envolveu estudantes e professores de diferentes áreas do conhecimento (Geografia, História, Educação Física, Português, Teatro, Artes Visuais) e teve como objetivo a instalação de um espaço de debate e reflexão sobre a questão do racismo.

Nesse processo, o grupo discutiu exaustivamente os padróes e estereótipos que vigoram nos ambientes que frequentamos, bem como a influência da mídia na construção de nossas identidades. Assim como no trabalho Book da Turma, apresentado anteriormente, o tema da padronização, da homogeneização, esteve presente, ainda que sob outro viés, consolidando a percepção de que, muitas vezes, tentamos, até mesmo sem perceber, nos adequar a determinada imagem ou comportamento identificado como superior (mais "bonito", mais "bem-sucedido", mais "popular"). Vieram à tona situaçóes de desvalorização e discriminação vividas por diversos estudantes e professores em função de suas diferenças em relação ao padrão dominante.

\section{Figura 4}

Não existe cor certa II, Porto Alegre, 2014.

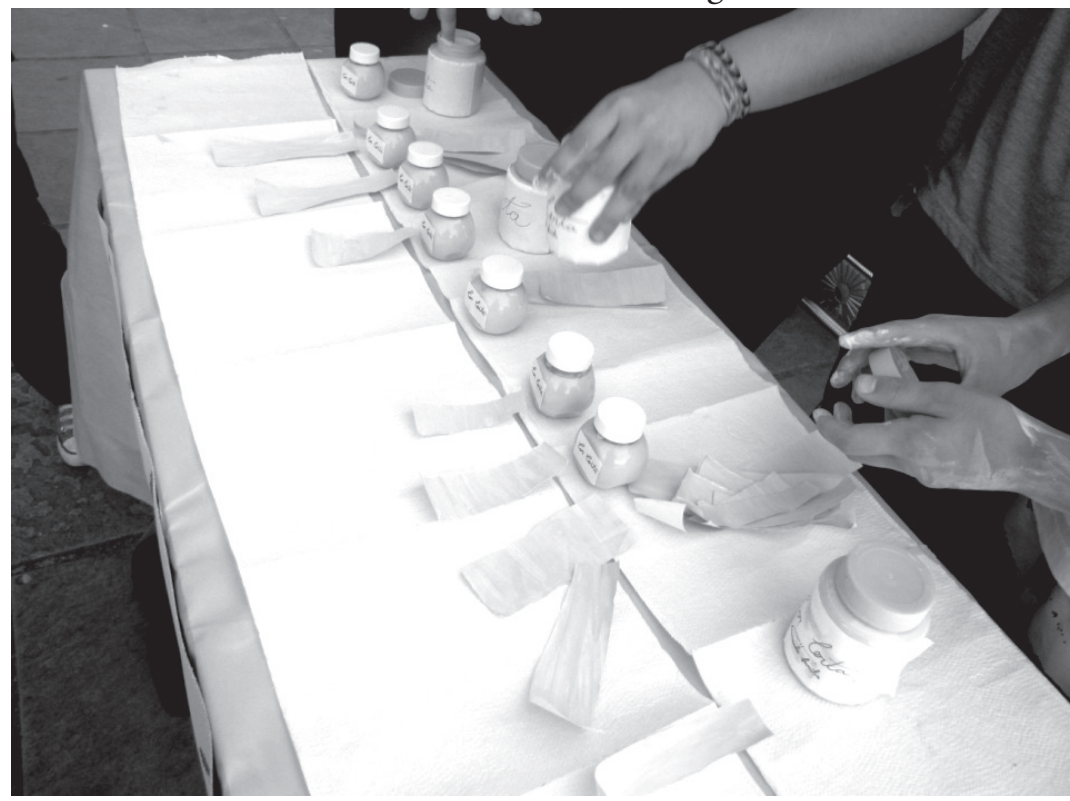

Fonte: Mônica Torres Bonatto. 
Não apenas a história que está nos livros didáticos nos auxiliou a aprofundar o debate sobre o tema da negritude, mas também nossa própria história, agora compartilhada com o grupo. Debatemos muito. $\mathrm{O}$ que constitui um ato racista? $\mathrm{O}$ que pode ser considerado apenas brincadeira, aceita em determinados grupos? Quando uma piada perpetua situaçóes de discriminação? Isso não me diz respeito? Qual o papel de políticas públicas como, por exemplo, as cotas raciais para ingresso nas universidades ou em concursos públicos?

Como era de se esperar, após vários meses de trabalho, não chegamos a posiçóes unânimes sobre as questôes abordadas; entretanto, como grupo, acordamos que o tema da negritude é tratado de maneira superficial ou, ainda, é ignorado em muitas instituiçóes de ensino e na sociedade em geral. Discordamos em alguns aspectos da discussão, mas concordamos em não compactuar com o silêncio em torno do tema. Resolvemos compartilhar com outros estudantes da escola parte do nosso percurso.

Como fazê-lo? A provocação era para que nos colocássemos em movimento. Corpos em ação. Pensamento-ação.

Até aqui havíamos estudado modelos de comportamento, analisando os papéis desempenhados pelos indivíduos em diferentes situaçóes e dedicando especial atenção ao modo como a cor da pele, em algumas culturas, determina a posição do indivíduo na sociedade. Ao longo das atividades (que não estiveram circunscritas a nenhuma disciplina específica, mas ganharam espaço próprio), nós nos aproximamos dos Estudos da Performance, em especial quando investimos no entendimento de que comportamentos são socialmente construídos, e não naturalmente determinados. Nosso grupo ensaiava, ainda que isso náo fosse nomeado, tomar a performance como lente para analisar comportamentos e situaçôes observadas em nosso cotidiano.

Para a realização da performance, a turma de estudantes do $7^{\circ}$ ano do ensino fundamental em 2014, com idades entre 12 e 14 anos, dividiu-se em três grupos. O primeiro deles foi composto por vendedores de um produto fictício, batizado como A Cor do Sucesso (uma tinta solúvel em água, cujo nome, conforme consta na etiqueta, é "amarelo pele". Essa cor equivale à cor conhecida como "salmáo", que, por muito tempo, recebeu - e ainda recebe - a denominação de "cor da pele"). Segurando cartazes com frases provocadoras e gritando palavras de or- 
dem, o segundo grupo manifestou seu repúdio à venda de um produto como esse, que buscaria padronizar a cor das pessoas. O terceiro grupo, de "repórteres" e "cinegrafistas", registrou o evento, realizado na hora do recreio, em frente à porta que leva ao pátio da escola. A intenção era provocar colegas de outras turmas a pensar sobre o tema do racismo.

Noções até então inéditas em nosso repertório ganharam força: cada produção é um evento, único, sem possibilidade de reprodução; os espectadores são alçados à condição de participantes do evento, assim como em trabalhos do teatro contemporâneo; rompe-se com a necessidade de linearidade, visto que as experiências vividas por cada um dos envolvidos são necessariamente diferentes; destaca-se a importância do contexto político e social nas produçóes e o caráter autobiográfico de muitos trabalhos. Tais elementos, por si só, quando relacionados à educação, sugerem uma miríade de possibilidades.

A constituição de um grupo de jovens e adultos, estudantes e professores, trabalhando em colaboração, surge como uma chave ao entendimento do ensino como performance, dando força à convocaçáo para a construção de um posicionamento crítico frente às práticas mantidas por meio da reprodução de modelos e papéis cristalizados.

\section{ESCOLA COMO ENTRELUGAR}

Espaços carentes de identidade, pouco confortáveis sob diversos aspectos, planejados para receber vários grupos, sem acolher a nenhum deles, as salas de aula trazem a marca do abandono e do não pertencimento. Aos estudantes resta buscar estratégias de afirmaçáo da sua presença. Desenhos, frases e palavras soltas são gravados nas paredes, portas, cadeiras e classes como evidências de sua existência que tentam escapar ao processo de uniformização e contenção. Para além dessas inscrições, tornadas visíveis ao menos por determinado período, interessa pensar nos corpos escolarizados, suas marcas e formas de resistência (MCLAREN, 1992) e, mais do que isso, na performance como espaço de posicionamento crítico e político.

Segundo Peter McLaren, "[...] a resistência dos estudantes indica que existe uma ruptura nos rituais de ensino" (MCLAREN, 1992, p. 235), incoerências e contradiçốes que são percebidas por eles e, de certa 
forma, denunciadas. Tais ações são construídas em oposição à obrigatoriedade de permanecer sentado por horas e horas a que são submetidos seus corpos, à padronização dos gestos, ao silêncio em relaçáo às suas opinióes. $\mathrm{O}$ autor diz que

[...] todo corpo carrega uma história de opressão, um resíduo de dominação, preservado nos estratos após estratos de um tecido que respira. [...] A hegemonia, que se inscreve nos símbolos fisionômicos dos corpos dos estudantes e se transformam em gestos, são um ato de corporeidade (MCLAREN, 1992, p. 229).

As restrições físicas impostas pela nossa cultura educacional em sala de aula sobre estudantes e professores provocam marcas que seráo sentidas fora dela (PINEAU, 2013, p. 42). Na esteira do pensamento sobre corpo desenvolvido na pesquisa de McLaren, Elyse Pineau declara:

Eu quero chamar a atençáo para como a performance afina e atenua nossos sentidos cinéticos e sinestésicos em relação às nossas fisicalidades habituais e também às dos outros. Ao prestar atenção não apenas ao que o corpo faz em sala de aula, mas a que significados e valores sociais responde esse corpo, a pedagogia performativa pode intervir nos rituais da escolarização sobre os quais não pensamos (PINEAU, 2010, p. 104).

Aqueles que voltam à escola como docentes trazem em seus corpos marcas dos processos de escolarização vividos, registros que, com frequência, são difíceis de reconhecer e, mais ainda, de alterar. A interação com os estudantes, frente à resistência oferecida aos processos a que os mesmos são submetidos, pode gerar espaços de ruptura, resultando em experiências transformadoras.

Esse diagnóstico da escola e do escolar, fornecido pela noçáo de performance, nos ajuda a compreender que, historicamente, a escola é marcada por esse apagamento do corpo, essa tentativa de silenciamento e contenção corporal que a caracterizam como lugar de produção per- 
formativa de sujeitos. Com efeito, os pesquisadores Jan Masschelein e Maarten Simons (2013), no livro Em Defesa da Escola, nos convidam a refletir sobre a instituição escolar, partindo do princípio de que

[...] a escola é uma invenção histórica e pode, portanto, desaparecer. Mas isso também significa que a escola pode ser reinventada, e é precisamente isso o que vemos como nosso desafio e, como esperamos deixar claro, a nossa responsabilidade no momento atual (MASSCHELEIN; SIMONS, 2013, p. 11).

Ao assumirem a tarefa de definir "o que é o escolar" (MASSCHELEIN; SIMONS, 2013, p. 25), os autores problematizam diversas percepçóes ativas no senso comum sobre o que é e para que serve a escola, tais como: lugar onde crianças e jovens são munidos com os conhecimentos necessários para garantir sua adaptação à sociedade; instituição criada para inserir as crianças no mundo; e espaço destinado à socialização e iniciação de acordo com as regras vigentes em determinada cultura. Masschelein e Simons, logo no início do texto, explicitam que seu objetivo não é "esboçar a escola ideal" ou mesmo proteger uma "velha instituição", mas sim "articular um marco para a escola do futuro" (MASSCHELEIN; SIMONS, 2013, p. 29).

Não são poucas as cobranças dirigidas a esse modelo educacional, sobre o qual pesam acusaçóes de alienaçáo dos envolvidos no processo de escolarização; de consolidação e manutenção de estruturas de poder e corrupçáo; de desmotivação da juventude; de falta de eficácia e empregabilidade a partir da visão da escola como negócio (MASSCHELEIN; SIMONS, 2013).

Vale mencionar, também, as constantes tentativas de domesticação da escola, com vistas a torná-la funcional para a sociedade. Entre as variantes desse processo, destaca-se a designação da escola como extensão da família e seu atrelamento ao mercado de trabalho (MASSCHELEIN; SIMONS, 2013, p. 27). Essa corrente lida com a percepção de que a escola é pouco permeável aos eventos que ocorrem fora dela, configurando-se como um espaço reservado, isolado. 
Uma das alternativas aqui apresentadas é justamente a performance que nos ajuda a identificar o panorama repetitivo produzido nas práticas escolares e a reorganizar tais práticas repetitivas, rompendo com elas performativamente (ou seja, em ação). Essa suspensão da repetição, característica da performance, é propícia a um repensar da escola, pois a escola é, ela própria, um momento de suspensão social.

$\mathrm{Na}$ escola podemos contar com a possibilidade da suspensão da ordem social, instituindo-se um tempo que não é tido como tempo produtivo, mas como tempo tornado livre (MASSCHELEIN; SIMONS, 2013, p. 33). No entanto, Masschelein e Simons ressaltam que tal suspensão não é "operativa na educação atual", ao contrário, nela predomina a busca pela adequação aos parâmetros de produtividade vigentes em nossa sociedade (MASSCHELEIN; SIMONS, 2013, p. 33).

A ideia de igualdade possibilitada pela escola, quando essa constrói o tempo livre, está ligada à criação de uma "brecha no tempo linear" (ao suspender ou adiar o passado e o futuro), rompendo com o momento de causa e efeito que o tempo representa, no qual as origens do estudante determinam necessariamente suas alternativas de futuro (MASSCHELEIN; SIMONS, 2013, p. 36). Os autores consideram que

[...] o espaço escolar não se refere a um local de passagem ou de transiçáo (do passado ao presente), nem a um espaço de iniciação ou de socialização (da família para a sociedade). Pelo contrário, devemos ver a escola como uma espécie de puro meio ou centro (MASSCHELEIN; SIMONS, 2013, p. 37).

A passagem de um estágio ou fase da vida a outro é marcada de várias maneiras, em diferentes culturas. $\mathrm{O}$ nascimento, a chegada à puberdade, o casamento, a conclusão de etapas da formação escolar e a maioridade legal, por exemplo, são alguns dos momentos de transformação que ganham um caráter ritualizado em nossa sociedade.

Essas situações de transição foram analisadas por Arnold Van Gennep (2012) no livro Ritos de Passagem, publicado originalmente em 1909, e descritas como rituais compostos por três fases: pré-liminar (se- 
paração), liminar (margem) e pós-liminar (agregação). A fase liminar, em especial, recebeu a atenção de antropólogos, como Victor Turner (1982), pois é nela que podemos identificar um momento de suspensão, em que o indivíduo não está mais na fase anterior ao início do ritual, tampouco completou o processo. Richard Schechner ressalta que, na fase liminar,

[...] as pessoas são despojadas de suas antigas identidades e lugares determinados no mundo social; elas entram num tempo-espaço onde não são nem-isto-nem-aquilo, nem aqui, nem lá, no meio de uma jornada que vai de um eu social a outro. [...] As pessoas internalizam suas novas identidades e iniciam-se em seus novos poderes (SCHECHNER, 2010, p. 63).

A noção de limen está relacionada a uma característica arquitetural que liga um espaço a outro, uma borda, arco ou peitoril. Schechner considera que, em muitos edifícios teatrais, o espaço do proscênio tem a função de conectar "[...] os mundos imaginários performados sobre o palco à vida diária dos espectadores em suas casas” (SCHECHNER, 2010, p. 65). Assim, “[...] um teatro vazio é liminar, aberto a todos os tipos de possibilidades - espaço que, por meio da performance, poderia tornar-se qualquer lugar" (SCHECHNER, 2010, p. 65).

É em função disso que propomos aqui a escola como entrelugar, ou seja, como espaço liminal, pois, de um lado, trata-se de uma zona rica em indefiniçóes, potencialmente bastante incômoda e até mesmo angustiante no cotidiano, levando os indivíduos a buscarem a solução ou desfecho rápido de tal situação; de outro lado, na arte e, possivelmente, na educação, esse pode ser um espaço/tempo desejável e potente. Assim, "[...] em performance rituais e estéticas, o espaço sutil do limen é expandido em um amplo espaço, de forma real, bem como conceitual. O que, normalmente, é apenas um 'estar entre', torna-se o local da ação" (SCHECHNER, 2010, p. 64). Na Arte da Performance, frequentemente os artistas se reposicionam intencionalmente em espaços liminares ${ }^{1}$ (GAROIAN, 1999, p. 40).

Dessa proposiçáo surge o importante entendimento de que a sala de aula pode se configurar como "[...] uma zona neutra, de cooperação, aceitação e confiança no intercâmbio de papéis de professor e estudante [que] possibilita o debate de ideias" (GAROIAN, 1999, p. 61). Ou seja, um entrelugar. 


\section{PROFESSOR-PERFORMER, ESTUDANTE-PERFORMER}

No cenário encontrado atualmente em muitas escolas, a arquitetura e o mobiliário utilizados garantem a manutenção das formas de ser e estar nesse espaço, constituindo-se como instrumentos de controle tanto sobre os estudantes quanto sobre os professores (MASSCHELEIN; SIMONS, 2013, p. 54-55): ambos os grupos cumprem suas rotinas, têm suas açóes roteirizadas e representam seus papéis, seguindo parâmetros culturalmente legitimados e refletidos na configuração que centraliza o foco na figura "à frente" da classe.

A performance, tomada como um comportamento ritualizado, permeado pelo jogo, tanto se oferece como lente teórica, quanto como método pedagógico aos educadores que investem na criação de currículos inclusivos, buscando o desenvolvimento do pensamento crítico, descentralizando a autoridade do professor, encorajando e criando condiçóes para o aprendizado interativo entre colegas e garantindo que todos os estudantes tenham igual acesso aos recursos educativos (PINEAU, 2013).

Performar a escola significa, nesse sentido, operar com a expectativa de que trabalhos realizados em colaboração guardam potencial para romper com as hierarquias mantidas há séculos nas instituições de ensino. Performar a escola nos leva a buscar a constituição da mesma como um entrelugar.

$\mathrm{Na}$ linha de pensamento construída até aqui, tomamos a noção de espaço liminal para pensar a sala de aula como espaço performativo e a educação como ato performativo, possibilitando o desenvolvimento de processos de ensino-criação. Tais processos trariam a marca da colaboração entre professores e estudantes, imbuídos de características dos participantes de uma performance.

McLaren e Garoian também partiram da noção de liminaridade para analisar as relaçóes entre professores e estudantes. Ao refletir sobre o papel de professor, McLaren (1992) destacou três tipos de performance nos rituais de ensino: o professor autoritário, para quem o conhecimento é lei; o professor entertainer/animador; e o professor servidor-liminar. Este último ganhou especial interesse de Garoian, pois se caracteriza como um provocador cultural, operando entre a cultura escolar e os diversos conteúdos que os estudantes trazem para a sala de aula, oriundos de suas experiências culturais. 
O servidor-liminar "[...] sabe que não deve meramente apresentar conhecimento aos estudantes; ele deve transformar a consciência dos estudantes, permitindo que eles 'encarnem' ou corporifiquem o conhecimento” (MCLAREN, 1992, p. 167). Seu objetivo é criar limiares/portais/ bordas expandindo os parâmetros do espaço liminal, habitando esse espaço polêmico de significados em disputa (GAROIAN, 1999, p. 43).

O que estamos desenhando aqui, fruto da relação da nossa prática docente com a teoria que embasou este trabalho, é uma proposta de radicalização do processo de ensino-criação, em especial pela flexibilização dos papéis professor/estudante e pela provocação para pensarmos novas formas de atuação na educação básica.

Cientes de que a relação que está sendo tratada envolve adultos e crianças, ou adultos e jovens, que não estão em momentos iguais de desenvolvimento e formação, a noção de reversibilidade aponta para um desejável equilíbrio entre indivíduos com posiçôes distintas. Ao pensar professores e estudantes como performers estamos tomando-os como colaboradores em criação, relativizando hierarquias e gerando novas possibilidades de transformação.

Em um processo de ensino-criação, tal flexibilização das hierarquias se dá a partir do momento em que não há apenas uma voz de comando, mas uma coordenação realizada em colaboração, com os riscos que tais práticas impóem. As definiçóes se dão em ação, em performance.

Ao definir sua experiência como docente no ensino superior, Eleonora Fabião apresenta a noção de professor-performer, que aqui tomaremos emprestada, aplicando-a à realidade da escola de educação básica. Ela diz:

[...] ser professora é parte do meu projeto artístico. [...] Como professora-performer meu trabalho é propor e vivenciar experiências. Tais experiências visam o desenvolvimento e a integração das capacidades orgânicas, criativas e comunicacionais do atuante (performer, cidadão, sujeito histórico, vivente) e visam seu fortalecimento por meio do aumento da agilidade, flexibilidade e disponibilidade. Considero a sala de aula um dos mais interessantes espaços performativos, pois que estabelecemos, de antemáo, um pacto colaborativo. Trata-se de um espaço de criação e experimentação, um microcosmo político a ser poeticamente e pedagogicamente explorado (FABIĀO, 2009, p. 66). 
O reconhecimento da performance como evento, e não como artefato ou obra, parte do entendimento de que sua criação acontece a partir da interação entre os participantes e que, portanto, nenhum deles tem total controle sobre ela. Quando a performance termina, está irremediavelmente perdida; ela é única e não pode ser repetida (FISCHER-LICHTE, 2014, p. 41-42).

Quando os temas nos quais estão profundamente implicados professores-performers e estudantes-performers ganham centralidade, as fronteiras entre quem ensina e quem aprende se tornam menos nítidas do que nos sistemas tradicionais de ensino. Distanciamo-nos das noçóes de professor-ator e estudante-espectador, por fazerem a manutenção de uma definição estanque de papéis, para nos lançarmos à ideia da reversibilidade de papéis na interação entre o professor-performer e o estudante-performer.

Não podemos ignorar o tom utópico de tais proposiçóes, tendo em vista que o sistema educacional, mantido por nós mesmos, é bastante resistente a alteraçóes estruturais que desorganizem as bases que reproduzem, há muitas décadas, a estrutura das instituições que reconhecemos como escolas. Entretanto, novamente aqui o caráter liminar desses eventos possibilita pensar em momentos de ensino-criação, eventos que se inserem justamente em brechas, frestas, rupturas, gerando vislumbres de outras formas de ser e estar na escola.

Participar de momentos de ensino-criação, em que professores e estudantes se colocam como performers, trabalhando colaborativamente, pode gerar o momento de suspensáo em que o tempo-espaço escolar é reinventado a partir da subjetividade e da ação dos participantes. São flashes da potência da performance no espaço escolar. É preciso lembrar que a

[...] Performance não é outra coisa senão a junção idiossincrática entre ser e fazer. Aquilo que a tradição educacional se esmerou em separar reencontra na Performance uma possibilidade infinita de variação, de criação. $\mathrm{O}$ corpo aparece não mais como algo a ser docilizado, mas como algo a ser potencializado, colocado no centro da atividade. Performance e Educação se fazem no corpo, com o corpo e para o corpo. Não há Performance sem o olhar do outro, portanto falamos aqui de um corpo compartilhado, partilhado na ação de fazer e olhar, interagir e reagir (ICLE, 2013, p. 21). 
Dessa forma, aproximar a performance da educação nos leva a questionar a manutenção de uma concepção de ensino com foco na transmissão de conhecimento, pois nesse encontro ecoa uma outra visão de educação: a de que "[...] educamos para transformar o que sabemos, não para transmitir o já sabido" (LARROSA; KOHAN, 2013 p. 5). Masschelein e Simons observam que,

[...] normalmente, vemos a educação como sendo orientada pelo objetivo e como provedora de direção ou de um destino. Isto implica que os adultos ditam o que as crianças ou os jovens (deveriam) fazer. Mas a educaçáo consiste muito mais em não dizer aos jovens o que fazer, é sobre transformar o mundo (coisas, palavras, práticas) em algo que fala com eles (MASSCHELEIN; SIMONS, 2013, p. 98).

Em um cenário em que as escolas são organizadas por disciplinas, gerando uma fragmentação que impossibilita a análise de determinados temas (pois esses não podem ser vistos isoladamente), “[...] campos pós-disciplinares como os estudos culturais e os estudos da performance surgem do momento e do afấ de relacionar o político com o artístico e com o econômico" (TAYLOR, 2011, p. 13).

\section{POR UMA PEDAGOGIA PERFORMATIVA}

A proposta de uma "pedagogia performativa" (PINEAU, 2010), na qual professores e estudantes não estão engajados na "busca por verdades", pauta tão cara à instituição escolar conforme a conhecemos, orienta a construção de "[...] ficçôes colaborativas - continuamente criando e recriando visões de mundo e suas posiçôes contingentes dentro delas" (PINEAU, 2010, p. 97).

A performance se coloca como uma possibilidade de reposicionamento das práticas educacionais, entendidas aqui como um conjunto mutável de narrativas - e não como acumulação linear de competências específicas de cada disciplina (PINEAU, 2005). Assim, a performance nos provoca a repensar tanto os currículos (não apenas escolares) quanto a 
manutenção da hierarquização de saberes, com base na consciência de que "[...] esses currículos — tradicionais, formais ou culturais — estão baseados, em geral, na seleção de saberes que devemos acessar e em elementos já estereotipados da cultura” (ICLE, 2013, p. 19). A dimensão política da performance, reforçada pela valorização da experiência coletiva, "[...] fica à mostra quando se experimenta uma ruptura com os saberes já institucionalizados e, sobretudo, com conhecimentos pensados como processos individuais" (ICLE, 2013, p. 19).

Assim, a noção de performance, entendida tanto como linguagem quanto como ferramenta de análise da ação humana, possibilita a reflexão sobre alguns aspectos da educação escolarizada e, a partir daí, pode nos levar a experiências diferentes daquelas proporcionadas por práticas tradicionais de ensino, geralmente centradas no professor e pautadas pela intenção de transmissão de conhecimento. Em vez de consolidarmos a escola como ambiente carente de identidade e sem significação ou relação com a realidade do estudante, talvez possamos pensá-la como espaço de transformaçấo e invenção, que não é parte da sociedade produtiva nem integra o núcleo da família, mas que tem potencial para a produção de alternativas inéditas.

Tal concepção de pedagogia traz consigo algo de radical, transformador, pois visa à intervenção e ao reposicionamento de professores e estudantes no cotidiano escolar. A performance convida ao risco, na medida em que não oferece formatos únicos, planos fixos, propostas pré-planejadas.

Quando as situações de ensino-aprendizagem assumem características observadas em proposiçóes performativas e a sala de aula passa a ser compreendida como espaço performativo, regido por um pacto colaborativo entre professores-performers e estudantes-performers, é constituído um laboratório de criação, aberto a experimentações que incluem o revezamento de papéis entre quem aprende e quem ensina; um espaço propício a exploraçóes de diferentes possibilidades de relação de professores e estudantes entre si e com o conhecimento.

\section{REFERÊNCIAS}

FABIÃO, E. Performance, Teatro e Ensino: poéticas e políticas da interdisciplinaridade. In: TELLES, N.; FLORENTINO, A. (Org.). Cartografias 
do Ensino do Teatro. Uberlândia: Editora da Universidade Federal de Uberlândia, 2009. p. 61-72.

FISCHER-LICHTE, E. The Routledge Introduction to Theatre and Performance Studies. New York: Routledge, 2014.

GAROIAN, C. Performing Pedagogy: toward an Art of Politcs. New York: State University of New York Press, 1999.

GENNEP, A.V. Ritos de Passagem. Petrópolis: Vozes, 2012.

ICLE, G. Da Performance na Educação: perspectivas para a pesquisa e a prática. In: PEREIRA, M.A. (Org.). Performance e Educação: (des)territorializaçóes pedagógicas. Santa Maria: Editora da UFSM, 2013. p. 9-22.

LARROSA, J.; KOHAN, W. Apresentação. In: MASSCHELEIN, J.; SIMONS, M. Em Defesa da Escola: uma questáo pública. Belo Horizonte: Autêntica, 2013. p. 5-6.

MASSCHELEIN, J.; SIMONS, M. Em Defesa da Escola: uma questão pública. Belo Horizonte: Autêntica, 2013.

MCLAREN, P. Rituais na Escola: em direção a uma economia política de símbolos e gestos na educação. Petrópolis: Vozes, 1992.

PINEAU, E.L. Teaching is Performance: reconceptualizing a problematic metaphor. In: ALEXANDER, B.K.; ANDERSON, G.L.; GALLEGOS, B.P. Performance Theories in Education: Power, Pedagogy and te the Politics of Identity. New Jersey: Lawrence Erlbaum Associates, 2005. p. 15-39.

. Nos Cruzamentos entre a Performance e a Pedagogia: uma revisão prospectiva. Educação e Realidade, Porto Alegre, v. 35, n. 2, p. 89-113, maio/ago. 2010.

Pedagogia Crítico-Performativa: encarnando a política da educação libertadora. In: PEREIRA, M.A. (Org.). Performance e Educação: (des) territorializaçôes pedagógicas. Santa Maria: Editora da UFSM, 2013. p. 37-58.

SCHECHNER, R. Performance: teoria \& practicas interculturales. Buenos Aires: Libro de Rojas, 2000.

. O que pode a Performance na Educação: uma entrevista com Richard Schechner. Educação e Realidade, Porto Alegre, v. 35, n. 2, p. 23-35, mar./ago. 2010. Entrevista concedida a Gilberto Icle e Marcelo de Andrade Pereira.

STUCKY, N.; WIMMER, C. Teaching Performance Studies. Carbondale: Southern Illinois University Press, 2002. 
TAYLOR, D. Introducción - performance, teoria y prática. In: TAYLOR, D.; FUENTES, M. Estudos Avanzados de Performance. Mexico: Fondo de Cultura Económica, 2011. p. 7-30.

TURNER, V. From Ritual to Theatre: the human seriousness of play. New York: PAJ Publications, 1982.

\section{NOTAS}

1. Garoian toma como exemplo o trabalho da artista Suzanne Lacy, por considerá-lo em sintonia com a proposta por ele defendida: de uma Pedagogia da Arte da Performance. $\mathrm{O}$ autor considera que os trabalhos de Lacy são exemplos de currículos performativos, pois criam um espaço liminal, no qual a comunidade pode desenvolver um discurso crítico (GAROIAN, 1999, p. 129). Lacy descreve a Arte da Performance com base em comunidades (community-based performance art), como açóes que subvertem a autonomia tradicional do artista, o objeto de arte e os espaços artísticos. Tais trabalhos são pautados pela colaboração entre artistas e comunidades culturalmente diversas, até aqui ignoradas pelo mainstream. As estratégias são as mesmas da Arte da Performance. $\mathrm{O}$ artista atua como mediador, levantando ideias dos membros da comunidade e organizando sua participação em trabalhos de arte que servem aos seus interesses (GAROIAN, 1999, p. 27).

2. As autorizaçóes para uso de imagens estão em conformidade com as normas de pesquisa do Colégio de Aplicação, da Universidade Federal do Rio Grande do Sul (UFRGS).

Recebido em 04 de outubro de 2016.

Aprovado em 23 de fevereiro de 2017. 